\title{
Polymorphism of the prolactin gene and its association with egg production traits in native Chinese ducks
}

\author{
Cui Wang ${ }^{1}$, Zhenhua Liang ${ }^{2}$, Wenhua Yu ${ }^{1}$, Yanping Feng ${ }^{1}$, Xiuli Peng ${ }^{1}$, Yanzhang Gong ${ }^{1}$, \\ Shijun Li ${ }^{1 \#}$ \\ ${ }^{1}$ Key Lab of Agricultural Animal Genetics, Breeding and Reproduction, Huazhong Agricultural University, Wuhan, \\ Hubei 430070, PR China \\ ${ }^{2}$ Hubei Key Laboratory of Animal Embryo and Molecular Breeding, Institute of Animal Husbandry and Veterinary, \\ Hubei Academy of Agricultural Sciences, Wuhan, Hubei 430064, PR China
}

Copyright resides with the authors in terms of the Creative Commons Attribution 2.5 South African Licence.

See: http://creativecommons.org/licenses/by/2.5/za/

Condition of use: The user may copy, distribute, transmit and adapt the work, but must recognise the authors and the South African Journal of Animal Science

\begin{abstract}
As a candidate gene related to egg production, prolactin plays a crucial role in the reproduction of birds. In this study, polymorphism of the prolactin gene was screened in six Chinese native duck breeds (Shanma, Shaoxing, Youma, Jinyun, Jingiiang and the $\mathrm{F}_{2}$ resource population of white Liancheng $\mathrm{X}$ white Kaiya) using PCR-SSCP and direct sequencing. The results showed that 12 SNPs were detected: C-213T in the 5'flanking region, A-1842G in exon 2, A-3869G in exon 4 and C-5961T in exon 5, T-295C, C-381A and A-412G in intron 1, T-2231C in intron 2, C-3949T, T-3988G and T-4009C in intron 4 and T-6052A in the 3' flanking region. The C-381A site and C-5961T site can be detected by XbaI and Pstl PCR-RFLP, respectively. Furthermore, the C-5961T mutation results in an amino acid conversion (Cys to Arg) in the functional domain and affects the existence of a heparin binding site (L-R-R-D-S-H-K). In the $\mathrm{F}_{2}$ resource population, association analysis demonstrated that the C-5961T polymorphism was significantly associated with egg production and egg weight, with the $\mathrm{CC}$ genotype associated with higher egg production and bigger egg weight than the CT genotype.
\end{abstract}

Keywords: Duck, prolactin gene, egg production traits, single nucleotide polymorphism

${ }^{\#}$ Corresponding author: lishijun@mail.hzau.edu.cn

\section{Introduction}

Prolactin $(P R L)$ is a single-chain polypeptide hormone that belongs to the growth hormone gene family and is synthesized mainly in the anterior pituitary of all vertebrates. In mammals, it regulates diverse biological functions including promoting the development of breast gland, inducing lactation, maintenance of pregnancy and impelling the development of embryos (Byrnes \& Bridges, 2005; Bonomo et al., 2007; Lu et al., 2010). In avian species, $P R L$ is a crucial hormone in induction and maintenance of incubation behaviour and regulation of the follicular development (Sharp et al., 1988; Reddy et al., 2002).

Since the chicken $P R L$ gene was cloned and sequenced (Watahiki et al., 1989), most studies focused on detecting polymorphisms in this gene. Recently, a large number of SNPs have been reported in the chicken PRL gene. Cui et al. (2006) obtained six SNPs (C-2402T, C-2161G, T-2101G, C-2062G, T-2054A and G-2040A) and a 24-bp indel (insertion-deletion) from direct sequencing and association analysis showed that the 24-bp indel was associated with egg production and chicken broodiness traits. Three mutations screened (C-1607T, C-5749T and T-5821C) by Liu et al. (2007) showed that there is a correlation between different haplotypes and egg production. In geese, three SNPs (A-401G, G-268A and T-266A) in the 5'-proximal region of $P R L$ gene have been screened and statistical analysis suggested that these polymorphisms have the potential to be utilized in molecular breeding for egg production (Jiang et al., 2009). All the above studies displayed that $P R L$ is an important candidate gene on egg production.

As an important agriculture poultry species, duck egg has become a source of protein in human diet, but the egg performance of some native duck breeds remains to be improved. In this study, we used six 
native duck breeds as materials to screen the polymorphisms of five exons and their flanking sequences of duck $P R L$ gene, then analyzed the correlation between the polymorphisms and the reproductive traits in an $\mathrm{F}_{2}$ resource population of white Liancheng $\mathrm{x}$ white Kaiya.

\section{Material \& Methods}

Blood samples from five native duck breeds were provided by the Institute of Animal Husbandry and Veterinary, Hubei Academy of Agricultural Sciences, namely the Shanma $(n=37)$, Shaoxing $(n=43)$, Jinyun $(n=37)$, Jingjiang $(n=86)$ and Youxian $(n=46)$. These five populations were raised outdoors and production records of every duck were not available. Samples from the $\mathrm{F}_{2}$ resource population of white Liancheng X white Kaiya $(\mathrm{n}=350)$ come from Hankou Jingwu Industry Garden Ltd. and were reared in cages in an open-sided house and subjected to conventional breeding management conditions. The traits recording included the body weight at the age of first egg, the age of the first egg and egg production of each individual duck. The egg qualities were measured at 295 - 300 days, and the measurements included egg weight, Haugh unit, egg index, percentage of yolk, percentage of albumen and shell strength (Zhang et al., 2005).

Genomic DNA was extracted using the phenol-chloroform-isoamyl alcohol method (Sambrook et al., 1998) and the amount of genomic DNA was evaluated by Spectrophotometer ND-1000 (Nano-Drop, USA), adjusted to a density of $50-300 \mathrm{ng} / \mu \mathrm{L}$ with TE buffer and then stored at $-20^{\circ} \mathrm{C}$ for PCR amplifications.

Based on the complementary DNA sequence of the duck (Anas platyrhynchos) (GenBank Accession no: AB158611), five pairs of primers were designed using Oligo 7 primer analysis software to amplify the duck $P R L$ gene (Rychlik, 2007), covering the full length of five exons and their flanking region sequences. Primer information is given in Table 1. The PCR reaction was performed in a $15 \mu \mathrm{L}$ final volume, containing 50 - $300 \mathrm{ng}$ of genomic DNA, $1 \times \mathrm{PCR}$ buffer, $0.5 \mu \mathrm{M}$ of each primer, $25 \mu \mathrm{M}$ of dNTPs, $2.0 \mathrm{mM} \mathrm{MgCl} 2$ and 0.2 units Taq DNA Polymerase (TakaRa, Dalian, China). Thermal cycling conditions were $5 \mathrm{~min}$ at $94{ }^{\circ} \mathrm{C}$ followed by 35 cycles of $30 \mathrm{~s}$ at $94{ }^{\circ} \mathrm{C}, 30 \mathrm{~s}$ at annealing temperature, $30 \mathrm{~s}$ at $72{ }^{\circ} \mathrm{C}$, and a common final extension at $72{ }^{\circ} \mathrm{C}$.

Aliquots of $5 \mu \mathrm{L}$ of the PCR products were mixed with $10 \mu \mathrm{L}$ of the denaturing solution (95\% formamide, $25 \mathrm{mM}$ EDTA, $0.025 \%$ xylene-cyanole and $0.025 \%$ bromophenol blue), heated for $10 \mathrm{~min}$ at $98{ }^{\circ} \mathrm{C}$ and chilled on ice rapidly. Denatured DNA was subjected to $10 \%$ PAGE (polyacrylamide gel electrophoresis) analysis, which was run with $1 \times \mathrm{TBE}$ buffer for $16 \sim 20 \mathrm{~h}$ at $4{ }^{\circ} \mathrm{C}$ under a constant voltage $(120 \sim 150 \mathrm{~V})$. The gel was stained with $0.1 \%$ silver nitrate and visualized with $2 \% \mathrm{NaOH}$ solution (Zhang et al., 2007).

The PCR products of two samples represented different PCR-SSCP genotypes were followed by purifying, transformation, cloning prior to sequencing. The sequences were aligned by DNASTAR package (DNASTAR Inc., Madison, WI, USA), restriction endonuclease sites were detected by using Primer premier 5.0 software (Lalitha, 2000).

Table 1 The primer sequences and annealing temperatures of $P R L$ gene

\begin{tabular}{|c|c|c|c|c|}
\hline $\begin{array}{l}\text { Primer } \\
\text { name }\end{array}$ & Primer sequences $\left(5^{\prime}-3^{\prime}\right)$ & Amplification region & Product size (bp) & $\operatorname{Tm}\left({ }^{\circ} \mathrm{C}\right)$ \\
\hline PRL-F1 & ААATTCССТСТCACAGTTACA & $23-439$ & 417 & 51.5 \\
\hline PRL-R1 & GATGCAGAGACAAGTTTCACC & & & \\
\hline PRL-F2 & AATCGAATGACTATGCTTGCC & $1608-2008$ & 401 & 52.0 \\
\hline PRL-R2 & TACTGAAGGGATTTTTATATG & & & \\
\hline PRL-F3 & CTTTTAGTGCTGACCATTGTT & $2111-2512$ & 402 & 50.5 \\
\hline PRL-R3 & CCCTCCGCTCTATCTCACACT & & & \\
\hline PRL-F4 & AAATAAATTCCTAGATCTCTG & $3643-4070$ & 428 & 51.0 \\
\hline PRL-R4 & TAACTGAATCTGAGAACTTTG & & & \\
\hline PRL-F5 & TGCAAACCATAAAAGAAAAGA & $5707-6106$ & 400 & 52.0 \\
\hline PRL-R5 & CAATGAAAAGTGGCAAAGCAA & & & \\
\hline
\end{tabular}


A total of 599 samples from the six duck breeds were subjected to genotyping analysis using the PCRRFLP technique. The PCR reaction was performed as described above. $3 \mu \mathrm{L}$ of the PCR products were digested overnight with 5 units of Xbal/Pstl (TOYOBO, Osaka, Japan) at $37{ }^{\circ} \mathrm{C}$, and the digested products were visualized on $1.5 \%$ agarose gels stained with ethidium bromide and visualized with ultraviolet light to record the genotype of each sample.

The frequency of genotypes and P-values for Hardy-Weinberg equilibrium test were estimated and calculated by the procedure FREQ in SAS system 9.1.3 (SAS Institute, Cary, N.C., USA) for $\chi^{2}$. Using the general linear model (GLM) procedures, associations between the SNP and egg traits were analyzed according to the following model: $Y_{i j}=\mu+S_{i}+G_{i}+e_{i j}$, where $Y$ is the observed values of egg traits; $\mu$ is the population mean; $\mathrm{S}$ and $\mathrm{G}$, are the fixed effects of sire family and genotype, respectively; $\mathrm{e}$ is the random error. The CORR procedure was applied to estimate phenotypic correlations among the egg traits. Values are considered significant at $P<0.05$ and are presented as least square means \pm standard error.

\section{Results}

Twelve SNPs were detected (Table 2), the C-381A site and C-5961T site were recognized by XbaI and Pst1 PCR-RFLP, respectively. The C-5961T mutation occurred in the functional domain of the PRL amino acid sequence and the resultant conversion of cysteine to arginine affects the existence of a heparin binding site (L-R-R-D-S-H-K).

The C-381A and C-5961T were selected to employ polymorphism analysis by using Xbal and Pst1, PCR-RFLP, respectively. As shown in Figure 1, PCR-RFLP using Xbal in PCR products being digested into three genotypes, GG (417 bp), TT (417 bp/354 bp) and TG (417 bp/354 bp/63 bp). Results of the chi-square fitness test indicated that Shaoxing and Jingiiang ducks were in Hardy-Weinberg equilibrium at this site; whereas for other detected populations, there were significant differences between the distribution theory and practical distribution of genotype in this site. Furthermore, these genotyping results displayed that allele $\mathrm{G}$ was in dominance in Shangma, Shaoxing, Jinyun, Jingjiang and Youma duck breeds, while allele $\mathrm{T}$ was in dominance in the $\mathrm{F}_{2}$ stocks (Table 3).

Table 2 The mutations on the PRL gene

\begin{tabular}{cccc}
\hline Location & Mutation & Region & $\begin{array}{c}\text { Restriction } \\
\text { enzyme site }\end{array}$ \\
\hline $213 \mathrm{bp}$ & $\mathrm{C} \rightarrow \mathrm{T}$ & 5' flanking region & no \\
$381 \mathrm{bp}$ & $\mathrm{C} \rightarrow \mathrm{A}$ & intron 1 & XbaI \\
$412 \mathrm{bp}$ & $\mathrm{A} \rightarrow \mathrm{G}$ & intron 1 & no \\
$1842 \mathrm{bp}$ & $\mathrm{A} \rightarrow \mathrm{G}$ & exon 2 & no \\
$2231 \mathrm{bp}$ & $\mathrm{T} \rightarrow \mathrm{C}$ & intron 2 & no \\
$3869 \mathrm{bp}$ & $\mathrm{A} \rightarrow \mathrm{G}$ & exon 4 & no \\
$3949 \mathrm{bp}$ & $\mathrm{C} \rightarrow \mathrm{T}$ & intron4 & no \\
$3988 \mathrm{bp}$ & $\mathrm{T} \rightarrow \mathrm{G}$ & intron 4 & no \\
$4009 \mathrm{bp}$ & $\mathrm{T} \rightarrow \mathrm{C}$ & intron 4 & no \\
$5961 \mathrm{bp}$ & $\mathrm{C} \rightarrow \mathrm{T}$ & exon 5 & Pst1 \\
$6052 \mathrm{bp}$ & $\mathrm{T} \rightarrow \mathrm{A}$ & 3' flanking region & no \\
\hline
\end{tabular}

As shown in Figure 2, PCR-RFLP at the Pstl locus resulted in the PCR products being digested into three genotypes CC(400 bp), TT(254 bp/146 bp ) and TC(400 bp/254 bp/116 bp). Results of the chi-square fitness test revealed that Shanma, Shaoxing and Jingyun ducks were in Hardy-Weinberg equilibrium, 


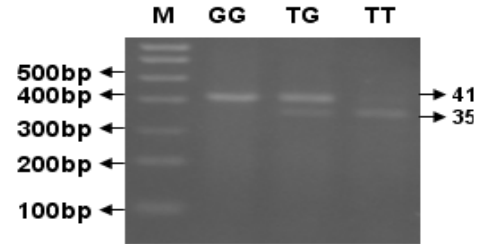

Figure 1 PCR-Xbal-RFLP results of duck $P R L$ gene. Three different genotypes (GG, TT, TG) are shown at the top (M: Marker1, a lane representing a fragment of $63 \mathrm{bp}$ not shown).

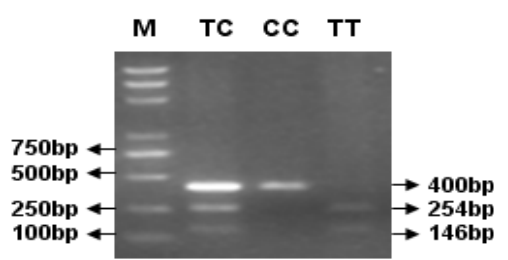

Figure 2 PCR-Pst1-RFLP results of duck $P R L$ gene. Three different genotypes (CC, TT, CT) are shown at the top (M: DL2000 plus).

Table 3 Distribution of Xbal genotypic and allelic frequencies between different breeds

\begin{tabular}{|c|c|c|c|c|c|c|c|}
\hline \multirow[t]{2}{*}{ Breeds } & \multicolumn{4}{|c|}{ Number of genotypes (frequencies ) } & \multicolumn{2}{|c|}{ Allelic frequencies } & \multirow{2}{*}{$\chi^{2}$} \\
\hline & TT & TG & GG & No & $\mathrm{T}$ & G & \\
\hline Shanma & $11(0.268)$ & $30(0.732)$ & 0 & 41 & 0.634 & 0.366 & $8.805^{*}$ \\
\hline Shaoxing & $20(0.476)$ & $21(0.500)$ & $1(0.024)$ & 42 & 0.738 & 0.262 & 2.981 \\
\hline Jinyun & $25(0.718)$ & $7(0.219)$ & 0 & 35 & 0.609 & 0.391 & $10.125^{* *}$ \\
\hline Jingjiang & $20(0.556)$ & $13(0.361)$ & $3(0.083)$ & 36 & 0.639 & 0.361 & 3.306 \\
\hline Youma & $23(0.793)$ & $6(0.207)$ & 0 & 29 & 0.603 & 0.397 & $9.966^{* *}$ \\
\hline $\mathrm{F}_{2}$ & $79(0.226)$ & $166(0.478)$ & $103(0.296)$ & 348 & 0.409 & 0.591 & $10.279^{* *}$ \\
\hline
\end{tabular}

Note: $\chi^{2}=0.05(2)=5.991, \chi^{2}=0.01(2)=9.210 ; * *$ indicates highly significant differences at $P<0.01$;

* indicates significant differences at $P<0.05$.

Table 4 Distribution of Pst 1 genotypic and allelic frequencies between different breeds

\begin{tabular}{cccccccc}
\hline \multirow{2}{*}{ Breeds } & \multicolumn{2}{c}{ Number of genotypes(frequencies) } & \multicolumn{2}{c}{ Allelic frequencies } & \multirow{2}{*}{$\chi^{2}$} \\
\cline { 2 - 6 } & TT & TC & CC & No & T & C & 0.431 \\
Shanma & $4(0.108)$ & $19(0.514)$ & $14(0.378)$ & 37 & 0.365 & 0.635 & 4.903 \\
Shaoxing & $4(0.093)$ & $28(0.651)$ & $11(0.256)$ & 43 & 0.419 & 0.581 & 0.431 \\
Jingyun & $4(0.018)$ & $19(0.514)$ & $14(0.378)$ & 37 & 0.365 & 0.635 & $58.61^{* *}$ \\
Jingjiang & $1(0.012)$ & $28(0.326)$ & $57(0.663)$ & 86 & 0.175 & 0.825 & $9.88^{* * *}$ \\
Youma & $8(0.174)$ & $10(0.217)$ & $28(0.609)$ & 46 & 0.283 & 0.717 & $200.28^{* *}$ \\
\hline
\end{tabular}

Note: $\chi^{2}=0.05(2)=5.991, \chi^{2}=0.01(2)=9.210 ; * *$ indicates highly significant differences at $P<0.01$. 
whereas Jiangjiang and Youma ducks and the $F_{2}$ resource population were in Hardy-Weinberg disequilibrium $(P<0.01)$. Moreover, these genotyping results indicated that allele $\mathrm{C}$ was in dominance in all detected duck breeds (Table 4).

Association analysis between the two Xbal polymorphisms and duck reproductive traits demonstrated that the shell strength of CC genotype was superior to those with other two genotypes $(P=0.076)$, while there was no significant association with any of the other reproductive traits $(P>0.05)$ (data not shown).

For the Pst 1 polymorphism, association analysis revealed significant association with egg production and egg weight $(P \leq 0.05)$ in the $\mathrm{F}_{2}$ resource population. The ducks of genotype CC possessed higher egg production $(P=0.032)$ and egg weight $(P=0.053)$ than those of the CT genotype (Table 5). The TT genotype was not detected in this population.

Table 5 Statistical analysis of $P s t 1$ genotypes and reproductive traits

\begin{tabular}{lrrr}
\hline Traits & CC(306) & \multicolumn{1}{c}{ TC(42) } & $P$ value \\
\hline Annual egg production (n) & $317.9^{\mathrm{a}} \pm 2.74$ & $297.1^{\mathrm{b}} \pm 11.6$ & $0.032^{*}$ \\
Age at the first egg (d) & $121.9 \pm 0.89$ & $119.8 \pm 2.39$ & 0.459 \\
Body weight at the first egg $(\mathrm{kg})$ & $1.79 \pm 0.240$ & $1.77 \pm 0.226$ & 0.614 \\
Egg weight $(\mathrm{g})$ & $72.0 \pm 0.25$ & $70.2 \pm 0.99$ & 0.053 \\
Haugh unit & $77.2 \pm 0.88$ & $76.2 \pm 2.63$ & 0.329 \\
Egg index & $1.345 \pm 0.009$ & $1.336 \pm 0.007$ & 0.241 \\
Percentage of yolk & $0.319 \pm 0.003$ & $0.324 \pm 0.007$ & 0.587 \\
Percentage of albumen & $0.536 \pm 0.003$ & $0.521 \pm 0.009$ & 0.112 \\
Shell strength $\left(\mathrm{kgf} \cdot \mathrm{cm}^{2}\right)$ & $4.184 \pm 0.069$ & $4.145 \pm 0.174$ & 0.868
\end{tabular}

Note: Within rows different superscripts $(\mathrm{a}-\mathrm{b})$ indicate significant differences $(P<0.05)$;

* indicates significant association at $P<0.05$.

\section{Discussion}

As a crucial hormone in the activation and maintenance of broodiness, $P R L$ performs an important role in reproductive performance. Since the sequence of the duck $P R L$ gene has been reported, the polymorphisms of this gene have been drawing attention (Kansaku et al., 2005). In the domestic breed of Gaoyou duck, a T-1326C mutation in intron1 was associated with egg weight at the age of 30 weeks and the proportion of double-yolk (Li et al., 2009). In Muscovy duck, two SNPs (T-3777C and A-3785G) were detected in exon 4, and found that there were significant differences between non-broodiness muscovies and broodiness muscovies, muscovies and bgducks in genotype frequencies (Wu et al., 2008). In this study, we did not detect the above polymorphism sites, although 12 novel SNPs were detected in six native duck breeds. The results revealed that the duck $P R L$ gene is rich in polymorphisms in these duck populations.

There is a heparin binding site located in a region that is rich in basic amino acid residues, which can bind heparin and affect the activity of protein (Seno et al., 1990). This heparin binding site has also been found in the functional region of the $P R L$ amino acid sequence in broiler chickens, dwarf chicken and turkeys (Hanks et al., 1989; Wong et al., 1991; Zhou et al., 2001). In this study, we found that the C-5961T mutation in the functional region of the $P R L$ amino acid sequence causes an amino acid change (cysteine to arginine) which affects the existence of this heparin binding site (L-R-R-D-S-H-K).

Comparing the genotype and allele frequencies of the Xbal site in six duck stocks, we found that the $\mathrm{G}$ allele was in dominance in Shangma, Shaoxing, Jinyun, Jingjiang and Youma duck breeds. However, allele $\mathrm{T}$ was in dominance in the $\mathrm{F}_{2}$ resource population. This different distribution of genotypes in different duck populations may be ascribed to the different genetic background of these populations. At the Pst 1 site, two genotypes were detected and the individuals of CC genotype possessed higher egg production and egg weight than those of CT genotype. Therefore, the CC genotype could be an advantageous genotype on egg production and egg weight of ducks. The fact that there were relatively fewer CT genotype ducks may be due 
to the high intensity of artificial selection and the disadvantaged genotype could have been eliminated gradually in the long-term breeding process.

In summary, we detected 12 novel SNPs on duck $P R L$ gene, and analyzed the genotype distribution on six native duck breeds. The association with egg production and egg weight inspires us to study the role of duck $P R L$ on the mechanism of egg formation and the follicular growing process in future research.

\section{Acknowledgement}

This work was supported by new faculty funding from the Ministry of Education of PR China No: 4010-071009 and open funding from the Hubei Provincial Key Lab No : 2007ZD01.

\section{References}

Bonomo, I.T., Lisboa, P.C., Pereira, A.R., Passos, M.C. \& de Moura, E.G., 2007. Prolactin inhibition in dams during lactation programs for overweight and leptin resistance in adult offspring. J. Endocrinol. 192, 339-344.

Byrnes, E.M. \& Bridges, R.S., 2005. Lactation reduces prolactin levels in reproductively experienced female rats. Horm. Behav. 48, 278-282.

Cui, J.X., Du, H.L., Liang, Y., Deng, X.M., Li, N. \& Zhang, X.Q., 2006. Association of polymorphisms in the promoter region of chicken prolactin with egg production. Poult. Sci. 85, $26-31$.

Hanks, M.C., Alonzi, J.A., Sharp, P.J. \& Sang, H.M., 1989. Molecular cloning and sequence analysis of putative chicken prolactin cDNA. J. Mol. Endocrinol. 2, 21-30.

Jiang, R.S., Zhang, L.L., Geng, Z.Y., Yang, T. \& Zhang, S.S., 2009. Single nucleotide polymorphisms in the 5 '-flanking region of the prolactin gene and the association with reproduction traits in geese. S. Afr. J. Anim. Sci. 39, 83-87.

Kansaku, N., Ohkubo, T., Okabayashi, H., Guemene, D., Kuhnlein, U., Zadworny, D. \& Shimada, K., 2005. Cloning of duck PRL cDNA and genomic DNA. Gen. Compar. Endocrinol. 141, 39-47.

Lalitha, S., 2000. Primer Premier 5. Biotech. Softw. Internet. Rep. 1, 270-272.

Li, H.F., Zhu, W.Q., Chen, K.W., Zhang, T.J. \& Song, W.T., 2009. Association of polymorphisms in the intron1 of duck prolactin with egg performance. Turk. J. Vet. Anim. Sci, 33, 193-197.

Liang, Y., Cui, J., Yang, G., Leung, F.C. \& Zhang, X., 2006. Polymorphisms of 5'-flanking region of chicken prolactin gene. Domest. Anim. Endocrinol. 30, 1-16.

Liu, H.G., Wang, X.H., Liu, Y.F., Zhao, X.B., Li, N. \& Wu, C.X., 2007. Analysis of the relationship between codon frequency of prolactin gene and laying performance in five chicken breeds. Progress in Biochemistry and Biophysics 34, 1101-1106. (abstract in English).

Lu, A., Hu, X., Chen, H., Jiang, J., Zhang, C., Xu, H. \& Gao, X., 2010. Single nucleotide polymorphisms in bovine PRL gene and their associations with milk production traits in Chinese Holsteins. Mol. Biol. Rep. 37, 547-551.

Reddy, I.J., David, C.G., Sarma, P.V. \& Singh, K., 2002. The possible role of prolactin in laying performance and steroid hormone secretion in domestic hen. Gen. Comp. Endocrinol. 127, 249-255.

Sambrook, J., Eritsch, E.F. \& Maniatis, T., 1998. Molecular Cloning: A Laboratory Manual [M], 2nd ed. Beijing: Science Press. pp. 592-601.

Seno, M., Sasada, R., Kurokawa, T. \& Igarashi, K., 1990. Carboxyl- terminal structure of basic fibroblast growth factor significantly contributes to its affinity for heparin. Eur. J. Biochem. 188, 239-245.

Sharp, P.J., Macnamee, M.C., Sterling, R.J., Lea, R.W. \& Pedersen, H.C., 1988. Relationship between prolactin LH and broody behavior in bantam hens. J. Endocrinol. 118, 279-286.

Watahiki, M., Tanaka, M., Masudam, N., Sugisakim, K., Yamamatom, M., Yamakawa, M., Nagai, J. \& Nakashima, K., 1989. Primary structure of chicken pituitary prolactin deduced from the cDNA sequence. Conserved and specific amino acid residues in the domains of the prolactins. J. Biol. Chem. 264, 5535-5539.

Wong, E.A., Ferrin, N.H., Silsby, J.L. \& Halawani, M.E., 1991. Cloning of a turkey prolactin cDNA: Expression of prolactin hormone throughout the reproductive cycle of the domestic turkey (Meleagris gallopavo). Gen. Comp. Endocrinol. 83, 18-26. 
Wu, X., Li, A., Wang, S.K., Wang, H., Jia, H.Y. \& Wang, G.Y., 2008. Correlation analysis between nucleotide polymorphism of the prolactin exon 5 and broodiness in ducks. Fujian J. Anim. Husband. Vet. 30, 6-9. (abstract in English).

Zhang, C.L., Wang, Y., Chen, H., Lan, X.Y. \& Lei, C.Z., 2007. Enhance the efficiency of single-strand conformation polymorphism analysis by short polyacrylamide gel and modified silver staining. Anal. Biochem. 365, 286-287.

Zhang, L.C., Ning, Z.H., Xu, G.Y., Hou, Z.C. \& Yang, N., 2005. Heritabilities and genetic and phenotypic correlation of egg quality traits in brown-egg dwarf layers. Poult. Sci. 84, 1209-1213.

Zhou, M., Zhang, X.Q., Shi, Z.D. \& Cao, Y.C., 2001. Cloning and sequencing of prolactin gene cDNA in three chicken breeds. Yi Chuan Xue Bao 28, 614-620. 